Referencia para citar este artículo: Leal, D. M., \& Macedo, J. P. (2019). Os discursos protetivos e punitivos acerca dos adolescentes em medida de internação no Brasil. Revista Latinoamericana de Ciencias Sociales, Niñez y Juventud, 17(1), 207-221. doi:https://dx.doi.org/10.11600/1692715x.17112

\title{
Os discursos protetivos e punitivos acerca dos adolescentes em medida de internação no Brasil ${ }^{*}$
}

\author{
DENISE MARIA LEAL \\ Jó̃o Paulo MaCEdo *** \\ Professor Universidade Federal do Piauí, Brasil.
}

Assistente social da Prefeitura Municipal de Teresina-PI e da Prefeitura Municipal de Timon-MA. Brasil.

Artículo recibido en enero 15 de 2018; artículo aceptado en marzo 20 de 2018 (Eds.)

- Resumo (analítico): objetiva-se apreender os sentidos de proteção integral no atendimento ao adolescente em medida de internação, modalidade de medida socioeducativa mais aplicada no Brasil na atualidade. Esta pesquisa foi realizada através de entrevista semiestruturada com oito trabalhadores e análise documental do PIA, RTA, evolução do caso, sentença, relatório de avaliação in loco e medida socioeducativa pública, no Centro Educacional Masculino (CEM) em Teresina-PI, Brasil. Sob a perspectiva da análise do discurso, apreendeu-se, com base nos resultados, que os sentidos de proteção integral adquirem caráter de punição, pela compreensão do ato infracional pela ótica individual, naturalizando os processos de violência e culpabilizando a família. Nessa lógica, os discursos protetivo e punitivo alternaram-se, como se fizessem parte de uma mesma lógica de intervenção.

Palavras-chave: juventude, atos infracionais, institucionalização, medidas socioeducativas (Thesaurus de Ciências Sociais da Unesco).

\section{Protective and punitive discourses on adolescents in detention in Brazil}

- Abstract (analytical): The present article aims to capture the meaning of comprehensive protection that is present in the treatment of adolescents who are in detention for having committed criminal acts. This study was conducted using semi-structured interviews with eight workers and a documental analysis of Individual Assistance Plans, Technical Evaluation Reports, files detailing the progress of cases, sentences, on-site evaluation reports and public socio-educational measures in the Male Educational Centre (MEC) in Teresina-PI, Brazil. Using a discourse analysis perspective, the results showed that the meanings around comprehensive protection were related to punishment, through the understanding of the infraction as the responsibility of the individual, the presence of violence in the young offenders' lives and blaming the family. In this logic, protective and punitive discourses were alternated, as if they were part of the same intervention logic.

\footnotetext{
* Trata-se de um artigo de pesquisa: «Proteção e punição: relações de tensão e complementariedade no campo da Proteção Integral ao adolescente que cumpre medida de internação», com financiamento da Capes, no Programa de Pós-Graduação em Políticas Públicas da Universidade Federal do Piauí, em 25/04/2017. Número da autorização do Comitê de Ética em Pesquisa da Universidade Federal do Piauí, que endossou a investigação ao análise que a mesma atendia aos padrões éticos em pesquisa (CAAE 57085916.3.0000.5214). Grande área: Ciências Sociais Aplicadas. Área: Estado, Sociedade e Políticas Públicas.

** Mestra em Políticas Públicas pela Universidade Federal do Piauí. Assistente social da Prefeitura Municipal de Teresina-PI e da Prefeitura Municipal de Timon-MA. Orcid: 0000-0002-4236-3382. Índice H5: 1. E-mail: denise_lealy@hotmail.com

*** Doutor em Psicologia pela Universidade Federal do Rio Grande do Norte. Docente do Programa de Pós-Graduação em Psicologia da Universidade Federal do Piauí, na linha Psicologia, Saúde Coletiva e Processos de Subjetivação, é bolsista de produtividade do CNPQ. Orcid: 0000-0003-43938501. Índice H5: 10. E-mail: jpmacedo@ufpi.edu.br
} 
Key words: Youth, delinquency, institutionalization, correctional education (Social Sciences Unesco Thesaurus).

\section{Los discursos protectivos y punitivos acerca de los adolescentes en medida de internación en Brasil}

- Resumen (analítico): el presente artículo tiene como objetivo aprehender los sentidos de protección integral en la atención al adolescente que cumple la medida de internación en el Centro Educativo Masculino (CEM) en Teresina-PI, Brasil. Esta investigación fue desarrollada a través de una entrevista semiestructurada con ocho trabajadores y el análisis documental del Plan Individual de Atención (PIA), del Informe Técnico Evaluativo (ITE), de las fichas de evolución del caso, de la sentencia, del informe de evaluación sobre in locus y de la medida socioeducativa pública. En la perspectiva del análisis del discurso, se aprehendió, con base en los resultados, que los sentidos de protección integral adquieren carácter de castigo, por la comprensión del acto infractor de la óptica individual, naturalizando los procesos de violencia y culpabilizando a la familia. En esa lógica, los discursos protector y punitivo se alternaron, como si formaran parte de una misma lógica de intervención.

Palabras clave: juventud, delincuencia, institucionalización, educación correccional (Tesauro de Ciencias Sociales de la Unesco).

\section{-1. Introdução. -2. Metodologia. -3. Resultados e discussão. -4. Conclusões. -Referências.}

\section{Introdução}

A lógica do capital insere um padrão de reprodução ampliada das contradições engendradas em seu centro, em face das desigualdades concretas entre as classes sociais que a põe em movimento. Como resultado desse processo, que não se esgota no âmbito econômico, mas repercute, por mecanismos ideológicos, nas múltiplas esferas da vida social, estão processos perversos que produzem a invisibilidade das inúmeras violações de direitos a que os sujeitos estão submetidos. Importa ressaltar que esses mecanismos se concretizam em face de um Estado com responsabilidades expressas em documentos normativos para exercer a função protetiva, mas, efetivamente atua como núcleo que efetua o controle político do capital, conforme aponta Mészáros (2011).

Essa é uma realidade que tem se apresentado cada vez mais latente na conjuntura dos países da América Latina, por estar «permeada de (...) políticas que partem de abordagens de controle social dissimuladas sob argumentos protetivos (...) (Rizzini, Corona, Llobet, \& Vale, 2016, p. 9), devido ao recuo do Estado nas suas funções no campo social.

Vivemos na contemporaneidade um tempo de emergência de conflitos sociais manifestados em escala mundial. São conjunturas pela violação de direitos em processos de reordenamento urbano que recuperam práticas recorrentes de higienismo social, repressão e militarização urbana, questões essas complexificadas na América Latina diante de frágeis processos democráticos instaurados após as experiências de ditaduras civil-militares na região. Neste cenário, processos de vulnerabilização da população se acentuam, sendo que na região a questão social tem sido historicamente marcada por sua dimensão etária associada a questões de classe, etnia, raça, gênero, local de moradia. Inúmeros atravessamentos autoritários perpassam a busca pela efetivação de direitos e pela ampliação de oportunidades equitativas para crianças, adolescentes e jovens em contextos de vulnerabilidade, via políticas públicas de proteção social (Rizzini et al., 2016, p. 9).

No Brasil, crianças e adolescentes, estiveram por anos submetidos a medidas essencialmente punitivas no atendimento às suas demandas, vinculadas ao Código de Menor. O Estatuto da Criança e Adolescente (ECA) inaugurou em 1990, na realidade brasileira, um novo padrão de atendimento, assentado nas mudanças doutrinárias consubstanciadas na Constituição Federal de 1988. Não se pode 
negar que o ECA, efetivamente, concretizou descontinuidades com o Código do Menor. Segundo a análise de Silva (2005a), por meio do ECA inaugurou-se um sistema de garantia de direitos infantojuvenis, instaurando procedimentos legais a serem adotados para o atendimento do adolescente que cometeu ato infracional.

Trata-se, nas palavras de Bazílio (2001), de um esforço para desjudicialização da criança e do adolescente, ou seja, de retirar as decisões unicamente da esteira do judiciário, destacando o papel da sociedade civil, por meio do Conselho Tutelar. As alterações também estão presentes no âmbito da gestão das políticas sociais voltadas para este segmento, com a introdução da participação popular e o destaque para o papel do Ministério Público na defesa dos direitos da criança e do adolescente, além da municipalização das políticas sociais. Cabe, entretanto, ressaltar que as alterações, fruto deste processo, estão inseridas no quadro maior de determinações capitalistas que, envolto numa aparência democrática, num discurso de garantia de direitos, continua a reproduzir a lógica da dominação, numa clara continuidade com a lógica inerente ao Código do Menor (Silva, 2005b).

A «proteção» da população infantil e juvenil percebida como «risco material e moral» foi concebida como um problema político de relevância, que ocupou o centro de debates na região. As formas institucionais e políticas de proteção social que emergiram destes debates articularam aspirações de integração social com sofisticados mecanismos de controle moral. Assim, em perspectiva histórica, as formas de definição da questão social das novas gerações associaram bem-estar e controle (...) Isto é, os conjuntos binários cuidado-controle, educação-castigo, governo-soberania não constituem oposições excludentes, mas sim duas faces da mesma moeda, no que se refere às formas de lidar com as vulnerabilidades sociais destes sujeitos de proteção, que são as crianças e os adolescentes (Rizzini et al., 2016, p. 10).

Por esse aspecto, a polarização entre a proteção e punição destinada a crianças e adolescentes na realidade dos países latino-americanos de forma mais ampla, e no Brasil em termos mais específicos, revela um processo de alteração nas próprias funções do Estado Moderno, sob um viés neoliberal, em que as medidas de proteção são cada vez mais precarizadas. A densidade das violações de direitos vivenciadas por meninas e meninos cotidianamente nesses países está intrinsicamente vinculada a uma realidade macrossocial produtora das contradições sociais sob a lógica do capital.

Nesse sentido, é característico que as expressões da questão social na realidade brasileira têm recebido um atendimento em que prevalecem a face de controle social e a individualização de processos que são sociais. A violência, exemplo claro dessa perspectiva, constitui uma complexa expressão da questão social, que possui raízes profundas no sistema social vigente, mantendo assim intocadas as estruturas sociais que tanto caracterizam o sistema «protetivo» de crianças e adolescentes no país. Entendemos que a questão social

evidencia hoje a imensa fratura entre o desenvolvimento das forças produtivas do trabalho social e as relações sociais que o impulsionam. Fratura esta que vem se traduzindo na banalização da vida humana, na violência escondida no fetiche do dinheiro e da mistificação do capital ao impregnar todos os espaços e esferas da vida social. Violência que tem no aparato repressivo do Estado, capturado pelas finanças e colocado a serviço da propriedade e poder dos que dominam, o seu escudo de proteção e disseminação. O alvo principal são aqueles que dispõem apenas de sua força de trabalho para sobreviver: além do segmento masculino adulto de trabalhadores urbanos e rurais, penalizam-se os velhos trabalhadores, as mulheres e as novas gerações de filhos da classe trabalhadora, jovens e crianças, em especial negros e mestiços (Iamamoto, 2011, p. 144).

Por outro lado, a invisibilidade que a questão social adquire nesse jogo de forças está articulada a uma visibilidade perversa (Sales, 2004) de sujeitos que, inseridos em ciclos de violência, somente ganham notoriedade na condição de autor. Esse processo está latente em toda a América Latina, onde a questão juvenil tem sido tratada de forma sensacionalista desvinculada da política e da democracia. As repercussões disso têm sido o reducionismo como é encarada a infância nesses países, bem como a banalização dos processos que a envolvem (Méndez, 2008). Como vimos, a individualização da 
questão social esconde e mascara a base social de sua formação, centrando responsabilidade na figura individualizada de setores pauperizados da sociedade.

No Brasil, temos acompanhados ao longo dos anos tentativas de empreender manobras na Constituição Federal de 1988, a reboque de governos e bancadas conservadoras, que visam restringir direitos sociais ao mesmo tempo em que objetivam manter veladas as contradições de base. As propostas de redução da maioridade penal se inserem nessa lógica, como desdobramento do fortalecimento dos setores conservadores no parlamento brasileiro «que pregam medidas como redução da maioridade penal, recrudescimento das penas e até pena de morte [...]» (Mena, 2015, p. 22). Os argumentos acerca da redução da maioridade penal resgatam aspectos psicológicos e do desenvolvimento dos adolescentes para justificar a suposta maturidade dos sujeitos para se responsabilizar por seus atos. Essas análises desconsideram a dimensão social de vivência de inúmeras violações de direitos no cotidiano desses jovens. Nesse sentido, focalizar uma única dimensão para a defesa da redução da maioridade penal serve para manter velada a intenção deste discurso: o enclausuramento dos indesejáveis.

A criminalização de adolescentes no Brasil segue números cada vez mais crescentes, segundo dados do Levantamento Anual do Sistema Nacional de Atendimento Socioeducativo (Sinase) (Brasil, 2017). A aplicação das medidas de restrição e privação de liberdade demonstra esse processo, com a prevalência da medida de internação, correspondendo a $66 \%$ das medidas socioeducativas aplicadas.

Ancorados neste cenário, de intensificação da questão social, os discursos resgatam na população os sentimentos de medo, insegurança e fazem o enfrentamento fluir pela perspectiva punitiva, amplamente defendida pela sociedade. Segundo pesquisa do Instituto de Pesquisa Datafolha (2015), $87 \%$ da população brasileira é a favor da redução da maioridade penal. Esses dados parecem indicar o avanço de ideias conservadoras que, aproveitando a sensação e o sentimento de insegurança da população, fortalece o discurso de punição daquele que comete ato infracional.

Os argumentos para a atribuição da responsabilidade pelo aumento da violência ao adolescente residem numa enviesada interpretação dos dados. Se atentarmos para os dados do Levantamento Anual Sinase (Brasil, 2017), os adolescentes em privação e restrição de liberdade representaram apenas $0,1 \%$ do total de adolescentes entre 12 a 18 anos no Brasil. Registra-se 24628 adolescentes em restrição e privação de liberdade em todo o país, sendo os crimes mais recorrentes os praticados contra o patrimônio, que envolvem roubo e furto. No geral, 44\% cometeram ato infracional análogo ao roubo, e $24 \%$ análogo ao tráfico de drogas, e somente $9 \%$ cometeram ato análogo ao homicídio. Ainda tomando como referência este levantamento, os adolescentes em cumprimento de medidas, $95 \%$ são do sexo masculino e 55,77\% são pretos ou pardos (Brasil, 2017).

$\mathrm{O}$ atendimento destinado aos adolescentes inseridos na condição de autor de atos infracionais sempre teve a marca punitiva no Brasil, que se revela tanto em seus mecanismos concretos, como culturais e ideológicos:

Imaginar uma unidade de internação em que adolescentes são mantidos aglutinados, sob situações humilhantes e de total falta de respeito aos direitos humanos, leva a sociedade a outro olhar tão cruel quanto em relação às próprias unidades, mas que agora se dirige diretamente aos próprios adolescentes privados de liberdade. Um olhar estigmatizante que os coloca como incapazes de mudar sua trajetória de vida, afastando-se da criminalidade (Padovani \& Ristum, 2016, p. 616).

Segundo a análise de Silva (2011), as ações carregam o eixo do controle sociopenal que se materializa, contraditoriamente, com o ECA. Trata-se da exacerbação da contradição ter no centro de um sistema protetivo ações pautadas unicamente no controle social, e que se efetivam por medidas eminentemente penais, exercendo, claramente, o controle do capital a partir da judicialização da questão social. Mesmo com o advento do ECA, o que temos visto, na verdade, é uma espécie de tutela jurídica penal do Estado ao adotar práticas que continuam a individualizar processos sociais, tendo como alvo, neste caso, os adolescentes pobres. Ademais, está subjacente a esse contexto um projeto 
societário específico que visa, por meio de uma perspectiva criminológica, relacionar pobreza com infração.

A alternância entre discursos protetivos e punitivos tem sido utilizada, em larga medida, para fornecer a aparência de legalidade tão cara aos mecanismos coercitivos prevalecentes para o atendimento dos adolescentes que cometem ato infracional no Brasil. Forjados sob uma base essencialmente disciplinar, que instrumentaliza a medida de internação, estes discursos estão arraigados numa estrutura social que historicamente construiu formas punitivas para atendimento das sequelas de um perverso sistema econômico e político em que a ação do Estado tem servido para atender aos interesses hegemônicos. Nessa perspectiva, cabe indagar, quais discursos os trabalhadores da medida de internação ancoram seu saber-fazer na execução da medida de internação.

Partimos nesse estudo do entendimento de que os discursos são canais por onde fluem processos ideológicos (Gondim \& Fischer, 2009) colocando em movimento estratégias que naturalizam processos sociais, bem como aquelas que expressam resistência ao seu avanço e empreendem um esforço de desconstrução de tais práticas. Deste modo, consideramos que os discursos, pela performatividade que portam em produzir sentidos e ressignificações, podem alternar, no caso do debate aqui proposto, elementos protetivos e punitivos como se os mesmos fizessem parte de um mesmo «paradigma» de intervenção. Esse é o pressuposto que orienta este estudo.

Assim, este artigo tem como objetivo analisar os sentidos de proteção integral, a partir dos discursos dos profissionais e dos instrumentos e medidas de proteção social voltados aos adolescentes em cumprimento de privação de liberdade. A recuperação destes elementos pode permitir acessarmos parte do universo de significados atribuídos à medida de internação pelos trabalhadores que atuam nesse campo, de modo a compreendermos os desafios aí postos.

\section{Metodologia}

A pesquisa teve natureza qualitativa, tendo em vista que seus objetivos estiveram vinculados ao conhecimento de significados, valores, sentidos produzidos pelos sujeitos em face de sua inserção em processos sociais que compõem a totalidade da vida social (Minayo, 2015). A análise dos sentidos de proteção integral, a partir de discursos produzidos pelos trabalhadores no campo da medida socioeducativa de internação, supõe uma dimensão de análise que considera que «[...] o modo de produção da vida material condiciona o processo em geral da vida social, política e espiritual. Não é a consciência dos homens que determina o seu ser, mas, ao contrário, é o seu ser social que determina a sua consciência [...]» (Marx, 1982, p. 25). Nessa perspectiva, a inserção dos trabalhadores na execução da medida de internação possui uma dimensão histórica de uma ação socialmente necessária. Essa bagagem histórica e cultural transparece nos discursos de proteção integral dos trabalhadores.

A pesquisa foi realizada no Centro Educacional Masculino (CEM), unidade pública, vinculada à Secretaria de Assistência Social e Cidadania (Sasc), gerida pelo governo do Estado do Piauí. O CEM é destinado a atender adolescentes, do sexo masculino, para cumprimento da medida de internação. Como procedimento para produção dos dados, identificamos que cada adolescente que cumpre medida de internação no CEM tem uma pasta onde estão reunidos todos os documentos do processo jurídico o qual responde. Deste modo realizou-se, num primeiro momento, análise documental do material produzido no próprio CEM, como o Plano Individual de Atendimento (PIA), Relatório Técnico Avaliativo (RTA) e evolução do caso e documentos produzidos no âmbito jurídico, mas que constavam nas pastas dos adolescentes que cumprem medida de internação no CEM, como Sentença, Relatório de Avaliação in loco e Medida Socioeducativa Pública. Para a seleção do material a ser analisado foi identificado os atos infracionais mais recorrentes pelos adolescentes em situação de internamento no CEM. O destaque foi para os tipos: homicídio qualificado, roubo majorado e latrocínio. Em seguida, selecionou-se duas pastas por ato infracional praticado, que contivessem os documentos produzidos tanto no CEM quanto no âmbito do judiciário, totalizando assim seis casos analisados. 
Quadro 1. Lista dos documentos que embasaram a análise documental

\begin{tabular}{|c|c|c|c|c|c|c|}
\hline $\begin{array}{c}\text { PASTAS } \\
\begin{array}{c}\text { Plano Individual de } \\
\text { Atendimento (PIA) }\end{array}\end{array}$ & PASTA 1 & PASTA 2 & PASTA 3 & PASTA 4 & PASTA 5 & PASTA 6 \\
\hline $\begin{array}{c}\text { Relatório Técnico Avaliativo } \\
\text { (RTA) }\end{array}$ & RTA 1 & RTA 2 & RTA 3 & RTA 4 & RTA 5 & RTA 6 \\
\hline $\begin{array}{c}\text { Evolução do caso } \\
\text { Evolução } \\
\text { do caso 1 }\end{array}$ & $\begin{array}{c}\text { Evolução } \\
\text { do caso 2 }\end{array}$ & $\begin{array}{c}\text { Evolução } \\
\text { do caso 3 }\end{array}$ & $\begin{array}{c}\text { Evolução } \\
\text { do caso 4 }\end{array}$ & $\begin{array}{c}\text { Evolução } \\
\text { do caso 5 }\end{array}$ & $\begin{array}{c}\text { Evolução } \\
\text { do caso 6 }\end{array}$ \\
\hline Sentença & Sentença 1 & Sentença 2 & Sentença 3 & Sentença 4 & Sentença 5 & Sentença 6 \\
\hline Relatório de avaliação in loco & RA 1 & RA 2 & RA 3 & RA 4 & RA 5 & RA 6 \\
\hline $\begin{array}{c}\text { Medida Socioeducativa } \\
\text { Pública }\end{array}$ & MSP 1 & MSP 2 & MSP 3 & MSP 4 & MSP 5 & MSP 6 \\
\hline
\end{tabular}

No segundo momento foi realizado entrevista semiestruturada, com oito trabalhadores do CEM, que atuam há mais de 10 anos no serviço. As entrevistas foram identificadas de forma abreviada pela letra $\mathrm{S}$, seguida da sequência numérica adotada. Como critério de inclusão selecionou-se os profissionais com formação de nível médio e superior em áreas distintas que se disponibilizaram para participar do estudo.

A análise dos documentos e entrevistas foi realizada com base na perspectiva dialética, compreendendo que «o discurso, por si só, é de natureza tridimensional, abarcando a linguagem, a história e a ideologia. Sua produção acontece na história, por meio da linguagem, uma das instâncias por onde a ideologia se materializa» (Gondim \& Fischer, 2009, p. 11). A análise, nesse sentido, possibilitou entrecruzar os discursos proferidos pelos sujeitos ancorados numa base histórica e ideológica que permite e dar sentido à produção dos mesmos em pelo menos três eixos discursivos: os significados atribuídos à medida de internação pelos trabalhadores; a alternância entre discursos protetivos e punitivos; e a naturalização centrada na família. Os padrões éticos foram observados e respeitados nesse estudo, tendo a pesquisa sido aprovada no Comitê de Ética de Pesquisa da UFPI sob a CAAE 57085916.3.0000.5214.

\section{Resultados e discussão}

a) Significados atribuídos à medida de internação a partir do olhar dos trabalhadores

As concepções sobre a medida socioeducativa foram igualmente coletadas por meio de análise documental e entrevistas. Os dados revelam uma análise do ato infracional que se evidencia, preponderantemente, pela periculosidade do sujeito, analisado pela sua autoria e pelo modo operacional de sua ação, descrito largamente nos documentos de origem dos operadores do judiciário. A medida de internação deve, portanto, servir de punição ao ato infracional, bem como favorecer práticas de disciplina, controle, ajustamento da conduta do adolescente.

Verifico, no caso em tela, que a adoção da cautelar máxima é a medida que se impõe, verificada a personalidade do menor, voltada à prática delituosa e à gravidade da conduta deflagrada [...] é forçoso reconhecer, não sem lamentar, que o adolescente agia com extrema habilidade, como se fosse um contumaz na prática criminosa, de posse de uma arma de fogo municiada, que era apontada para a cabeça das vítimas, conforme está assentada em seu depoimento [...] e nas declarações das vítimas [...] (Sentença 6) 
O discurso jurídico resgata uma compreensão do ato infracional pela ótica individual. A aplicação da medida socioeducativa de internação responde, ainda, à necessidade de atender a um clamor social, ou mesmo servir de exemplo para evitar novos atos.

Considero que diante do caráter hediondo do crime que resta devidamente provado e a sua repercussão social, seria prejudicial, tanto para o menor, quanto para os demais membros da sociedade local, a aplicação de medida socioeducativa que não fosse a de internação, uma vez que poder-se-ia criar uma noção errônea de proporcionalidade entre a infração cometida e a medida aplicada, levando a sociedade pensar que a infração em tela (homicídio qualificado e estupro de vulnerável) não se revestiu de gravidade e que por isso mesmo poderia ser praticado novamente com consequência branda (liberdade assistida ou outra medida que não a de internação). (Sentença 4)

$\mathrm{O}$ ato infracional se relaciona, nesses discursos, a uma personalidade infratora. Nessa perspectiva, é frequente a apresentação do ato infracional relacionado ao uso de substâncias psicoativas, como acontece no PIA 6, ou, ainda, a apresentação da frieza do adolescente ao praticar o ato infracional. Essa análise do ato infracional apresentada conduz à decretação da medida socioeducativa, que resgata a gravidade do ato infracional, e, através do ECA, autoriza a medida socioeducativa de internação no CEM (Sentença 3).

Os discursos presentes nas metas prescritas nos documentos que compõem o prontuário de cada adolescente internado apontam o controle e o respeito à disciplina:

Cumprimento das regras da Unidade; [...] manter bons relacionamentos com os demais adolescentes e funcionários [...] Comprometer-se a participar de forma efetiva das atividades propostas pela instituição, sobretudo a escola formal; propiciar abertura a novos hábitos em consonância com respeito, limites e regras; facilitar o processo ao entendimento da medida de internação, bem como ao ato infracional praticado. (PIA 2)

O ECA, instrumento cuja orientação básica é a proteção integral ao adolescente, resume-se a mera instrumentalidade legal-normativa para justificar a medida socioeducativa de internação, tendo em vista a compreensão que se tem da função dela. No trecho em destaque, as metas estabelecidas para o adolescente possuem viés de manutenção da ordem, da disciplina e de adequação dos comportamentos ao que é esperado, espécie de deveres. Essa concepção de medida socioeducativa ganha contornos ainda mais profundos na fala de alguns entrevistados.

Eu sempre digo que eu acho que três anos para se socializar, se reeducar eu acho pouco. [...] A única coisa que a gente não pode mudar é o caráter dele, infelizmente [...] porque ele já vem formado até os cinco anos de idade e aqui nós não recebemos adolescentes com menos de 13 anos de idade. Porque se a gente recebesse, poderia ser até uma forma melhor de conduzir ele, porque até cinco anos se forma o caráter. (S4)

O discurso em voga rearticula uma compreensão da questão social vinculada aos valores dos sujeitos numa linha desenvolvimentista psicológica, vinculando diretamente o ato infracional a uma questão de escolha, como se dentre todas as oportunidades e acessos possíveis em suas vidas, o que não é uma realidade para muitos desses adolescentes, os mesmos optassem deliberadamente pelo ato infracional. A compreensão do ato infracional deveria levar em consideração toda a conjuntura social que serviu de cenário para o desenvolvimento do sujeito e de suas práticas. Ao contrário disso, a instituição expressa movimentos discursivos que refletem padrões socialmente instituídos, servindo para manter veladas as contradições sociais.

Como consequência, a medida socioeducativa acaba por revestir-se de um caráter assistencial curativo (Silva, 2011). Para a autora, apesar de sua pretensa face «socioeducativa», as medidas acabam por efetivar o «(...) controle sociopenal dos adolescentes com processos infracionais», demonstrando o quanto o ECA tem sido utilizado, em larga medida, como o Código Penal é utilizado para o adulto (Silva, 2011, p. 161). Nos processos de medidas socioeducativas executados no estado de São Paulo, a autora identificou «semelhanças conceituais e operacionais» entre a medida socioeducativa aplicada e as medidas assistenciais, que por anos foram executadas no Brasil sob um padrão da situação 
irregular que individualiza a responsabilidade do sujeito pela vivência das múltiplas expressões da questão social, com viés claramente punitivo (Silva, 2011, p. 162).

A análise da medida socioeducativa, portanto, está intrinsecamente vinculada à compreensão que se tem de ato infracional e do adolescente. Como o ato é compreendido como resultado de valores do sujeito, de seu caráter, chega-se ao ponto de avaliar, na opinião de alguns entrevistados, que se a medida de internação fosse destinada também às crianças, fase em que se forma o seu caráter, a medida seria mais efetiva. Tal aspecto revela o quanto as instituições que deveriam assumir caráter protetivo transformaram-se em instâncias de controle, de adestramento do sujeito, combinadas com uma realidade maior de exclusão (Faleiros, 2007).

Percebe-se que a concepção da medida de internação adotada nos discursos que acompanhamos ao longo desse estudo ancora-se na ideia de que as medidas têm a capacidade de introduzir novos valores sociais por meio da imposição de rotinas institucionais, ao estabelecer normas, regras e sanções que limitam individualidade potencialmente perigosas. Tais pressupostos indicam análises parciais, fragmentadas e preconceituosas, que individualizam responsabilidades ao mesmo tempo em que massificam o atendimento ofertado, tendo em vista que os adolescentes são vistos de uma maneira uniforme, envolvidos em atos infracionais, devido ao seu caráter e ausência de limites familiar.

Ademais, os discursos sugerem que em meio as ações e atividades realizadas nas unidades de internação, percebem em alguns casos certa superação individual das condições que conduziram ao ato infracional. Frequentemente apontam para o comprometimento do sujeito com a mudança, respeito às normas e regras institucionais, além de o fato dos adolescentes se disporem a refletir sobre o ato infracional cometido. Na opinião de alguns entrevistados, além da instância de disciplina e controle, o tempo de cumprimento da medida internação acaba por propiciar ao adolescente uma reflexão acerca da sua própria vida e necessidade de mudança após uma análise de consciência e das atitudes morais que têm tomado.

Com base no exposto, analisar os meandros da medida de internação no Brasil, a partir de um caso específico da realidade piauiense, mas que encontra ressonância em outras realidades já analisadas por outras investigações, permite descortinar os aparentes enfoques socioeducativos que só têm funcionado, em larga escala, em nível de retórica. Na prática, o que existe é um sistema que reatualizou sua linguagem, mas continua operando valores que se pensavam superados.

\section{b) Alternância entre discursos protetivos e punitivos}

O elemento que mais se destacou nesse segundo bloco de análise foi a alternância entre discursos protetivos e punitivos em torno dos adolescentes em medida de internação. A utilização do termo «menor» em meio a um discurso que reconhece direitos específicos de sujeitos em fase de desenvolvimento, sinaliza bem essa alternância: «Determino que o menor seja recolhido em local apropriado e seja imediatamente encaminhado para Teresina-CEM, onde existe condições de se obedecer às recomendações do Estatuto da Criança e do Adolescente (ECA) quanto ao cumprimento da medida de internação» (Sentença 4, grifo nosso).

Nos documentos oriundos do âmbito jurídico, é frequente, ainda, a apresentação do adolescente como infrator, numa aparente tentativa de atualizar o termo menor: «[...] A autoria é induvidosa e converge para o adolescente infrator [...]» (MSP 6). O uso conjugado destas palavras revela o peso que o ato infracional tem na apresentação do adolescente, reatualizando concepções do Código de Menores (Vavassori \& Toneli, 2015).

Alguns discursos escapam da tônica da maioria, ao considerarem, minimamente, o adolescente que cumpre medida de internação no CEM como sujeito em processo de desenvolvimento. Entretanto, nesse mesmo discurso, a condição da mudança de conduta aparece reificando uma individualização do processo social:

[...] eu tinha curiosidade de chegar lá olhar o ato infracional dele e às vezes com outros companheiros, a gente especulava e falava a respeito, e aí, com o passar dos dias, você vai 
amadurecendo aquela ideia. Tem hoje adolescentes que eu olho assim, alguns dados daquele adolescente, mas eu só vejo na pasta do prontuário dele o ato infracional em si, eu não me adentro para saber como foi o modo operacionais daquele momento em que ele praticou o ato. Eu não faço muita questão de ver, justamente para mim não ter uma concepção de que ele é ruim por total [...] você percebe que se você for achar que ele é realmente, é um infrator, muitas vezes você vai pelo senso comum, e você não vê a pessoa que está por trás daquele rótulo [...] Então, assim, se você vê aquele adolescente enquanto processo de desenvolvimento pessoal, cognitivo e tudo, você vê que tem condição sim de mudanças de conduta daquele jovem. (S2)

Entretanto, também foi possível identificar, na fala dos sujeitos entrevistados, uma compreensão ampla do adolescente e do processo que o conduziu ao ato infracional:

[...] Mas se você for ver bem ao pé da letra, muitos desses adolescentes, eles têm «ns» problemas sociais que às vezes levam [...] eu vejo que os adolescentes que estão privados de liberdade até também como vítimas de..., algumas vezes não em todos os casos, de uma sociedade que é muito consumista, que cobra muito a gente, que você precisa ser bem de vida, ser bonito, e você precisa ter um monte de coisas pra você se enquadrar nos padrões sociais que a sociedade exige das pessoas [...] (S5)

A proteção integral, por sua vez, é analisada como sendo um incremento para a inserção do adolescente em situações que o conduzem ao ato infracional.

[...] essa porção de direitos que ele tem eu acho que..., não sei cada um tem seu ponto de vista. No meu, eu acho que isso aí de certa forma até incentiva para eles continuarem nessa vida que eles começaram a viver. Acho que deveriam ser mudadas algumas coisas, principalmente esse caso aí da maioridade [...] muitos alegam que ia superlotar os presídios, como já está no caso, a custódia tem capacidade para 350, tem 930. Mas eu acho que é uma forma de melhorar a maioridade penal ser reduzida para os 16 anos. (S6)

O apelo à redução da maioridade penal aparece no discurso de alguns trabalhadores como espécie de restrição ao «excesso de direitos» que o adolescente teria na legislação brasileira. Essa percepção é adensada pela lógica de individualização da questão social, num apelo que não está restrito ao Brasil, povoando também outros países da América Latina. Esse discursos e propostas de redução da maioridade penal significam o aprofundamento de medidas punitivas e esvaziam o sentido de proteção integral subjacente à medida de internação.

O discurso punitivo resgata, nessa perspectiva, a proteção como sendo um entrave social, tendo em vista que incentiva os adolescentes à prática de atos ilícitos. O trabalhador segue sua análise demonstrando que o nível de proteção social garantido pelo aspecto normativo impede a execução pelo Estado da medida de internação de forma efetiva:

[...] Em alguns casos sim, porque são muitos direitos que eles têm. Deveres são poucos, mas direitos... Se você ler o ECA você vai ver que eles (os adolescentes) são cheios de direitos. Então eu creio que dá para desempenhar alguns, não 100\%, isso eu acho impossível em qualquer casa de internação. (S6)

A grande maioria dos entrevistados aponta, nesse sentido, a proteção como prevalecente no CEM. Aqui não tem punição. Onde é que na tua casa você faz seis refeições por dia [...] Eles têm atendimento, a psicologia, coisa que acho que nem eu nunca fui em um psicólogo. E todo ser humano necessita da psicologia. [...] Quando eles adentram aqui, nunca na vida deles, ou por falta de oportunidade ou por não dar conta disso, nunca foram em um médico, eles chegam aqui, eles têm a oportunidade de ir no médico. [...] ] atendimento odontológico, coisa que eles nunca na vida viram um dentista. Sentir dor, não a gente não deixa eles sentirem dor aqui, quando reclamam que estão sentindo dor, aqui eles são atendidos. Então, aonde que extramural acontece isso? Não acontece. Então, aqui não é punitivo. Punitivo é quando pra você ter o seu alimento, você vai ter que trabalhar pra ele, você vai ter que plantar, depois que colher você vai comer. Isso aí é punição. É você deixar o adolescente sentir dor lá ou sangrar 
e se machucar e deixar lá, se omitir. Não é não? Aqui não tem punição. Aqui são muito bem tratados. Adolescente chega aqui com diabetes, anemia, verminoses, tudo é tratado. (S4)

A análise desses discursos demarca categorias sociais que estabelecem relações de poder na sociedade do capital. A este processo, alguns trabalhadores empreendem um movimento que busca romper com estereótipos. Entretanto, a alternância entre discursos protetivos e punitivo (re)produz o controle que se objetiva estabelecer com a medida de internação. Na concepção de Silva (2011, p. 41), o controle social:

[...] Trata-se de uma construção sócio histórica que permanece estruturada na divisão do trabalho sob o domínio do capital. Essa construção (re)produz as relações sociais desiguais, que a todo custo conformam a sociedade como uma sociedade de controle, que vai da «tolerância repressiva à defesa liberal da repressão» [...] e a sociabilidade que dele decorre é autoritária, consumista e individualizada, exercida de maneira extremamente danosa, perversa $[\ldots]$

Ainda que o trabalhador tenha uma ampla compreensão do adolescente e do processo que o conduziu ao ato infracional, a ação que opera dentro de um sistema que articula medidas de controle social produz uma sociabilidade individualizante e perversa, que visa atender aos determinantes mais gerais na qual se insere.

A análise empreendida nesta pesquisa, de abordagem materialista dialética, considera a condição de trabalhador a que estão submetidos os profissionais que atuam no CEM, sujeitos ao mesmo processo de alienação material e ideológica imposto a todos que vivem do trabalho. Entretanto, o trabalhador, enquanto sujeito social, possui a capacidade reflexiva de ultrapassar os limites ideológicos a que está submetido. Apesar de existir um significativo alinhamento nos discursos dos trabalhadores no CEM, ainda é possível encontrar análises que vão de encontro ao discurso corrente.

A inserção na dinâmica institucional favoreceu esta percepção de que os discursos oscilam verbalmente, como também as práticas oscilam no cotidiano. A polarização que marca esta análise é evidente no cotidiano do CEM. Revestidos de papéis sociais que almejam, em última instância, garantir que a proteção integral se efetive, os trabalhadores são invadidos pela onda punitiva, rearranjando discursos, adequando-o a situações específicas. Estas análises estão atreladas a um controle social que se efetiva via cultura do controle:

[...] embora as estruturas de controle tenham sido transformadas em importantes aspectos, a mudança mais significativa se deu no nível da cultura, que dá vida a estas estruturas, ordena seu uso e cunha seu significado. Um padrão retrabalhado de assunções cognitivas, compromissos normativos e sensibilidades emocionais está agora inscrito no campo, motivando a ação das agências de controle do crime, dando novo propósito e significado às suas práticas e alterando os efeitos e a significação simbólica de sua conduta. Sem um design ou articulações explícitas pré-constituídas, as coordenadas culturais do controle do crime têm sido paulatinamente modificadas, alterando a forma pela qual os agentes do sistema penal pensam e agem, e conferindo novo significado ao que eles fazem e dizem [...] (Garland, 2008, p. 376).

O controle adquire, sob esse aspecto, um caráter mais fluido, que atravessa os trabalhadores deste campo de discursos que instrumentalizam ações políticas dos sujeitos. A atual conformação das ações do Estado, que mesclam uma aparência protetiva e uma realidade punitiva, está diretamente ligada a uma cultura de controle do crime (Garland, 2008, p. 377), que ultrapassa os trabalhadores: "Onde quer que as intervenções reabilitadoras sejam realizadas, hoje em dia seu caráter é bem diferente do que antes. Elas focam mais questões relacionadas ao controle do crime do que ao bem-estar do indivíduo $[\ldots] \gg$.

O poder coercitivo do campo revela-se, portanto, também no trabalhador, que tolhe a sua fala, as suas análises e até mesmo o seu compromisso com o sujeito a quem destinam suas ações, para não ir de encontro aos padrões institucionalizados. Os discursos já revelam uma densa carga punitiva, que traz invisibilidade a toda dor e sofrimento provocados por mecanismos punitivos que mesmo 
não estando mais tão evidentes, revelam-se ainda mais perversos. Nessa perspectiva, o discurso do trabalhador, aparentemente neutro e destinado a atender a uma medida de caráter essencialmente pedagógico, revela-se como mais um instrumento de controle penal dos adolescentes.

\section{c) Naturalizar o processo, culpabilizar à família}

Observou-se, a partir dos documentos pesquisados, que as peças elaboradas pelos operadores do direito e equipe técnica normalmente iniciam pela descrição das condições de vida, de como se deu seu desenvolvimento pessoal, e como cada adolescente começou a se envolver em situações que possam tê-lo levado ao cometimento de ato infracional. É comum os documentos e os relatos das entrevistas evidenciarem um discurso uniforme ao se remeter ao adolescente que comete ato infracional, partindo da ideia de serem oriundos de família desestruturada, permeada de conflitos e situações de violência, com os pais envolvidos com uso de substâncias psicoativas. Nesse sentido, a família ganha significativo destaque na compreensão dos trabalhadores como lócus de desvio dos adolescentes, como podemos acompanhar em uma das entrevistas realizadas.

A maioria dos adolescentes que adentram, eles vêm de famílias pauperizadas, vêm sem escolaridade, pais separados, criados por avós, algum abuso doméstico, violência doméstica, abuso de... dependentes... de substâncias psicoativas. Então, poucos vêm de famílias com a base familiar bem posicionada. São poucos, contam-se nos dedos. (S2)

Merecem destaque determinadas entrevistas que conduzem ao entendimento de que o ato infracional é de responsabilidade do adolescente e de sua família, pois esta não se constituiu num núcleo forte o suficiente para evitar que o mesmo se envolvesse com a criminalidade e atos de violência.

A questão é justamente a convivência. A maioria tem pai ou mãe desestruturados, ou não tem pai e mãe e mora com algum parente, ou o parente deixa solto na rua e faz o que quer. Como eu falei, é criado na rua. Aí na rua você sabe que só aprende o que não presta. Aí de lá vai vendo as convivências e vai começando a furtar, aí depois a roubar, aí depois a matar, e vira um adolescente infrator. E acaba vindo para cá. (S8)

Ao tomar o envolvimento dos adolescentes com atos infracionais tendo como pano de fundo a responsabilização no indivíduo e na família, tal compreensão não apresenta e aprofunda a análise das condições que propiciaram estes processos, reatualizando a dicotomia abandono e infração nas quais são necessárias ações integradoras (Santos, 2008).

A apresentação das situações de pobreza a que os adolescentes estão submetidos é frequente. A maioria daqueles que estão em medida de internação encontram a pobreza como vivência cotidiana. Pobreza em sua dimensão material, de bens e acesso a consumo, mas também que dificulta a reprodução de suas condições de subsistência, haja vista a baixa escolaridade, baixa condição de acesso a bens e serviços públicos. A esse respeito, Mioto e Prá (2015, p. 150) colocam que:

[...] as famílias não se encontram nas mesmas condições materiais e culturais, e com isso as possibilidades de usufruírem dos serviços também se tornam desiguais. Tanto para avaliá-los e negociar sobre as condições e qualidade dos serviços ofertados, quanto para a combinação de recursos para usufruir dos serviços [...]

Nesse sentido, a desigualdade impacta fortemente as famílias de adolescentes que cumprem medida de internação. Esse processo repercute não somente no campo do cuidado, das responsabilidades da família, como requer a concepção hegemônica, mas também, nas possibilidades de questionamentos, de mobilização pela garantia de direitos de sujeitos que já não contam com o respaldo social.

A naturalização, ainda que não se constitua num processo histórico linear, depreende uma reatualização contemporânea que, mesmo a reboque de tensões, rupturas e adaptações, fornece certa legalidade ao discurso dos trabalhadores do CEM. Esse campo discursivo constitui, contemporaneamente, a justificativa mais inquestionável para o encarceramento dos pobres, ao vincular pobreza e criminalidade atrelada a valores morais. A análise de Wacquant (2001) sobre 
esse processo aponta que a criminalização da pobreza faz parte da alteração do próprio Estado Moderno, que, abrindo mão de sua face social, centra força numa intervenção penal sobre a classe trabalhadora, criminalizando a miséria. No Brasil, a medida socioeducativa de internação concretiza essa perspectiva, haja vista a prevalência do enfoque punitivo no cumprimento da medida e os dados que atestam o recorte de classe na sua execução (Leal \& Macedo, 2017).

Entretanto, na dimensão da medida de internação, a família é chamada a exercer a sua responsabilidade pelo processo socioeducativo, conforme prevê o Sistema Nacional de Atendimento Socioeducativo (Sinase) (Brasil, 2012). Famílias já fragilizadas por processos de violações de direitos são inseridas em ciclos crescentes de responsabilização, num processo que as centraliza no âmbito das políticas sociais na contemporaneidade. Conforme aponta Teixeira (2015, p. 218):

Sem dúvida, é importantíssima a centralidade da família nas políticas sociais, mas na direção da inclusão social (e não de reforço de papéis clássicos, histórica e culturalmente divididos por gêneros) e da oferta de uma rede intersetorial de serviços para atender suas necessidades e demandas que de fato possa garantir a vida familiar e evitar rupturas e violações de direitos $[\ldots]$

Nos discursos analisados está presente, portanto, uma relação de poder que impõe a responsabilização da família como principal núcleo de provisão de bem-estar de seus membros, denominado de familismo (Esping-Andersen, 2000). Os desdobramentos dessa perspectiva são mais perceptíveis no cotidiano de serviços que executam provisões de cuidado (Mioto \& Prá, 2015), como no setor da saúde e da política de assistência social. A conjuntura neoliberal tem intensificado o processo de afastamento do Estado de suas funções, centrando em núcleos secundários a provisão de bem-estar.

As repercussões desse quadro, entretanto, fazem-se sentir até mesmo em serviços que não possuem a família como um elemento central, como é o caso das medidas de internação. As análises dos trabalhadores são unânimes em perceber, no fracasso deste núcleo, o elemento que desencadeou o ato infracional, ainda que nessa família se reflita um processo maior de ausência de uma efetiva rede de provisão de segurança social, que deveria ser oferecida pelo Estado.

No âmbito do atendimento socioeducativo, a lei que regulamenta o Sinase prevê que devem constar no PIA, «[...] atividades de integração e apoio à família e formas de participação da família para efetivo cumprimento do plano individual» (Lei n. 12594 de 2012). Entretanto, efetivamente, o recurso à família se atém à compreensão superficial da situação familiar, explicação das normas e regras do atendimento numa articulação de mecanismos disciplinares.

A profundidade que alcançam na atualidade as expressões que envolvem o adolescente que cumpre medida de internação é analisada pelos trabalhadores através de discursos que resgatam essa compreensão de família, limitando a visão do sujeito e tendendo a universalizar as histórias de cada família. A análise sempre recorrente, tanto nas entrevistas como nos documentos de atendimento produzidos no CEM, a compreensão do sujeito como parte de uma família desestruturada é elucidativa dessa perspectiva. Existe, segundo a análise de Teixeira (2015, p. 228):

[...] a vivência do paradoxo entre a família idealizada e reconhecida formal e juridicamente como a confirmação saudável e legítima (a «normal», ou «nuclear», heterossexual, monogâmica e patriarcal) e família real efetivamente vivida pelos pobres e que os profissionais desqualificavam como «desestruturadas» ou «irregulares».

Os discursos dos trabalhadores tendem a desqualificar as relações familiares, desrespeitando as diferentes composições, relações, arranjos que constituem as famílias na contemporaneidade. O discurso do trabalhador, «[...] naturaliza e despolitiza a pobreza e a inibe de respeitar, política e ideologicamente, as diferenças presentes nos núcleos familiares» (Teixeira, 2015, p. 228).

Ao longo desse percurso foi possível identificar a ausência de análises acerca do adolescente, enquanto sujeito em desenvolvimento. Existe uma concentração no ato infracional praticado. Estas análises ainda evidenciam o tipo de sujeito que esses discursos expressam: um sujeito pronto, acabado, 
que recebeu determinadas condições da família e se desenvolveu a partir delas. A pesquisa de Alves, Pedroza, Pinho, Presotti e Silva (2009) apontou que estes discursos povoam as propostas de redução da maioridade penal no Brasil.

Nos documentos, a vinculação, no discurso, da pobreza com a criminalização, conduz a uma evidente naturalização dos processos que conduzem o adolescente ao ato infracional. A própria família narra uma trajetória solitária, valorativa, que serviu de base para o envolvimento do adolescente com o ato infracional. A produção desses discursos, tanto pela família, bem como a sua aceitação inquestionável pelo trabalhador, na produção dos documentos essenciais ao desenvolvimento da medida de internação, acarreta uma despolitização das violações a que este sujeito esteve submetido, bem como dos objetivos da medida de internação.

O processo de culpabilização do pobre pelas expressões concretas vivenciadas não é recente. Ainda que os mecanismos contemporâneos sejam bem mais fluidos e menos evidentes, a permanência da desqualificação dos sujeitos por sua condição de pobreza afeta o cotidiano da medida de internação no CEM. A participação, enquanto possibilidade de inserção política das famílias é tolhida por discursos generalizantes, que no máximo descrevem as condições de desenvolvimento dos sujeitos.

Os discursos dos trabalhadores da medida de socioeducativa de internação evidenciaram a necessidade de um maior investimento nos recursos humanos, no sentido de proporcionar momentos de formações, discussões e análises que favorecem uma maior reflexão acerca do cotidiano de intervenção e das implicações sociais da aplicação da medida. Essa estratégia pode favorecer uma prática mais refletida por parte destes trabalhadores, executando a práxis fundamental a sua intervenção. Essa possibilidade de trazer para o debate as implicações da medida de internação não significa individualizar no trabalhador a responsabilidade por todas as incoerências das medidas socioeducativas, mas possibilitar o desvelamento de seus mecanismos junto à quem as põem em movimento.

\section{Conclusões}

A análise aqui empreendida apontou para um sistema que historicamente tem operado uma medida de internação que se destina aos mecanismos de controle do capital, que se efetiva por meio de um poder disciplinar que objetiva, em última instância, inserir os adolescentes na lógica do capital.

Os anos de inserção do paradigma da Proteção Integral no Brasil, através do ECA e da regulamentação das medidas socioeducativas no Sinase não repercutiram em significativas mudanças. A concepção da medida permanece arraigada em padrões que se pensavam superados no Brasil. Ainda que seus mecanismos não estejam tão evidentes. $O$ tempo não caracterizou-se um elemento que conduzisse a medida de internação a uma superação de suas contradições. Ao contrário, parece cada vez mais latente um processo que insere a punição como um padrão interventivo sob uma aparência protetiva oferecida por discursos que resgatam um sistema formal inscrito em documentos normativos.

Os sentidos da proteção e punição buscados nessa pesquisa evidenciaram processos perversos de naturalização de discursos que reeditam análises de base moralista que alternam entre a ênfase punitiva e uma tentativa de revestir a mesma de aspectos protetivos. Esse movimento acaba por inscrever o trabalhador como um importante instrumento de controle social dos adolescentes, ou controle sociopenal, conforme apontou Silva (2011), tendo em vista que a sua prática não foge das determinações mais complexas na qual está inserida. Nessa lógica, seu discurso acaba por despolitizar um denso processo social a que os adolescentes que cumprem medida de internação estiveram submetidos.

A medida de internação adquire, portanto, sob essa ordem, o significado de proteção da sociedade e de produção de uma sociabilidade exigível sob a lógica do capital, de adequação de comportamentos, recuperando os discursos individualizantes de superação moral dos processos que conduziram ao ato infracional. Cabe, entretanto, analisar, que nível de proteção social se garante ao se efetivar a 
medida de internação sob este patamar? O cotidiano da medida socioeducativa de internação na contemporaneidade ressignifica o arcabouço protetivo por uma lógica do encarceramento dos adolescentes, visando efetivar o controle social por seu instrumento mais fluído e também mais instrumental: o cultural, que atravessa os trabalhadores numa lógica alienante que põe em movimento as estruturas de exploração e limpeza social pelo capitalismo.

\section{Agradecimentos}

Agradecemos à equipe do Centro de Educação Masculina-CEM e ao Coordenação de Aperfeiçoamento de Pessoal de Nível Superior (Capes) pelo incentivo financeiro para realizar este estudo.

\section{Referências}

Alves, C., Pedroza, R., Pinho, A., Presotti, L., \& Silva, F. (2009). Adolescência e Maioridade Penal: reflexões a partir da Psicologia e do Direito. Revista Psicologia Política, 9,67-83.

Bazílio, L. C. (2001). Avaliando a implantação do Estatuto da Criança e do Adolescente. O Social em questão, 6, 17-26.

Brasil. (2012). Lei $n^{\circ} 12$ 594, de 18 de janeiro de 2012. Institui o Sistema Nacional de Atendimento Socioeducativo (Sinase) e dá outras providências. Brasília, D. F.: Brasil. Recuperado de: http:// www.planalto.gov.br/ccivil_03/_ato2011-2014/2012/lei/112594.htm.

Brasil. (2017). Levantamento añual Sinase 2014: privação e restrição de liberdade. Brasília, D. F.: Secretaria de Direitos Humanos da Presidência da República. Recuperado de: http://www.sdh. gov.br/noticias/pdf/levantamento-sinase-2014.

Esping-Andersen, G. (2000). Fundamentos sociales de las economías postindustriales. Barcelona: Ariel.

Faleiros, V. P. (2007). Saber profissional e poder institucional. São Paulo: Cortez.

Garland, D. (2008). A cultura do controle: crime e ordem na sociedade contemporânea. Rio de Janeiro: Revan.

Gondim, S., \& Fischer, T. (2009). O discurso, a análise de discurso e a metodologia do discurso do sujeito coletivo na gestão intercultural. Revista do Centro Interdisciplinar de Desenvolvimento e Gestão Social-Ciags, 2(1), 9-26. Recuperado de: http://www.periodicos.adm.ufba.br/index.php/ cgs/article/view/75/pdf_1

Iamamoto, M. V. (2011). Cāital fetiche, questão social e Serviço Social. Serviço Social em tempo de capital fetiche: capital financeiro, trabalho e questão social. São Paulo: Cortez.

Instituto de Pesquisa Datafolha. (2015). 87\% aprovam redução da maioridade penal. São Paulo: Instituto de Pesquisa Datafolha. Recuperado de:

http:/datafolha.folha.uol.com.br/opiniaopublica/2015/06/1646200-87-aprovam-reducao-damaioridade.shtml

Leal, D. M., \& Macedo, J. P. (2017). A penalização da miséria no Brasil: os adolescentes «em conflito com a lei». Textos \& Contextos, 16(1), 128-141. doi:10.15448/1677-9509.2017.1.24550

Marx, K. (1982). Para a crítica da economia política: salário, preço e lucro. O rendimento e suas fontes. São Paulo: Abril Cultural.

Mena, F. (2015). Um modelo violento e ineficaz de polícia. In B. Kucinskiet (Ed.), Bala perdida: $a$ violência policial no Brasil e os desafios para sua superação (pp. 19-26). São Paulo: Boitempo.

Méndez, E. G. (2008). A dimensão política da responsabilidade penal dos adolescentes na América Latina: notas para a construção de uma modesta utopia. Educação e Realidade, 33(2),15-36.

Mészáros, I. (2011). A ordem da reprodução sociometabólica do capital. Para além do capital: rumo a teoria da transição. São Paulo: Boitempo. 
Minayo, M. C. de S. (Org.) (2015). Pesquisa social: teoria, método e criatividade. Petrópolis: Vozes. Mioto, R. C. T., \& Prá, K. R. D. (2015). Serviços Sociais e responsabilização da família: contradições da Política Social brasileira. In R. C. T Mioto, M. S. Campos, \& C. M. Carloto (Orgs.) Familismo direitos e cidadania: contradições da política social (pp. 159-163. São Paulo: Cortez.

Padovani,A. S., \& Ristum, M. (2016). Significados construídos acerca das Instituições Socioeducativas: enter o imaginado e o vivido. Psico-USF, 21(3), 609-622. doi:10.1590/1413-82712016210314

Rizzini, I., Corona, R. F., Llobet, V., \& Vale, J. B. (2016). Infância e juventude: processos de vulnerabilização e estratégias de resistência na América Latina. O Social em Questão, 35, 9-14. Recuperado de: http://osocialemquestao.ser.puc-rio.br/media/OSQ_35 Apresenta\%C3\%A7\%C3\%A3o.pdf

Sales, M. A. (2004). (In) visibilidade perversa: adolescentes infratores como metáfora da violência. (Tese de Doutorado em Sociologia). Universidade de São Paulo, São Paulo, Brasil. Recuperado de: http://www.teses.usp.br/teses/disponiveis/8/8132/tde-06122005-171140/pt-br.php.

Santos, G. (2008). Da lei do ventre livre ao Estatuto da Criança e do Adolescente: uma abordagem de interesse da juventude negra. Boletim do Instituto de Saúde, 44, 15-18. Recuperado de: http:periodicos.ses.sp.bvs.br/pdf/bis/n44/n44a05.pdf

Silva, M. L. O. (2005a). O Estatuto da Criança e do Adolescente e o Código de Menores: descontinuidades e continuidades. Revista Serviço Social \& Sociedade, 83, 30-48.

Silva, M. L. O. (2005b). O controle sócio penal dos adolescentes com processos judiciais em São Paulo: entre a 'proteção'e a 'punição'. (Tese de Doutorado). Pontifícia Universidade Católica de São Paulo, São Paulo, Brasil. Recuperado de: http://www.sapientia.pucsp.br/tde_busca/arquivo. php? codArquivo=944.

Silva, M. L. O. (2011). Entre proteção e punição: o controle sociopenal dos adolescentes. São Paulo: Editora Unifesp.

Teixeira, S. M. (2015). Política Social contemporânea: a família como referência para as Políticas Sociais e para o trabalho social. In R. C. T. Mioto, M. S. Campos, \& C. M. Carloto (Orgs.), Familismo direitos e cidadania: contradições da política social (pp. 211-239). São Paulo: Cortez.

Vavassori, M. B., \& Toneli, M. J. F. (2015). Propostas de Redução da Maioridade Penal: a Juventude brasileira no fio da navalha? Revista Psicologia: Ciência e Profissão, 35,1188-1205. doi:10.1590/1982-3703001732014

Wacquant, L. (2001). As prisões da miséria. Rio de Janeiro: Jorge Zahar. 